\title{
Understand the Role of Business Group Affiliation and Interlocking Directorates on Corporate Social Responsibility of Affiliated Firms: An Empirical Investigation
}

\author{
Dr.Santosh Kumar Tiwari ${ }^{1}$, Dr. Sudipta Sen ${ }^{2}$ \\ Jindal Global Business School, Sonipat, India
}

\begin{abstract}
This paper tries to bridge two literatures- Corporate Social Responsibility (CSR) and Business Group (BG), by investigating whether and when group affiliation influences the CSR of affiliated firms. For the present study I have used all the listed firms listed on NSE in India from 2010 to 2015 shows that group affiliation has a positive impact on CSR. The impact is more in older BG. Classifying interlocks (measured as degree centrality in network's director) of affiliated firms with other firms in the same group as internal and other interlocks as external, we have employed Generalized Method of Moments (GMM) to control for the endogeneity issue. We find that affiliated firms having higher ratio of external to internal interlocks would have higher CSR. Two aspects of business groupspromoter shareholding and diversity are considered important as they greatly affect the behavior of member firms. We have used them as boundary conditions and found that high promoter shareholding positively moderate the relationship while diversity has negative moderation on the studied relationship. The paper makes contributions to both business group and CSR literature and broaden our understanding towards group affiliated firm's behavior related to CSR activities.
\end{abstract}

Keywords: Business group, CSR, Emerging market 